\title{
Uso das novas tecnologias para a produção textual do gênero fotopoema em inglês
}

\author{
Alessandra Dutra () \\ Professora da Universidade tecnológica Federal do Paraná (UTFPR) \\ Givan José Ferreira dos Santos (1) \\ Professor da Universidade tecnológica Federal do Paraná (UTFPR) \\ Luciana Idalgo da Silva $\odot$
}

Mestre em Ensino de Ciências Humanas, Sociais e da Natureza pela Universidade Tecnológica

Federal do Paraná (UTFPR)

\section{Resumo}

Este estudo apresenta e discute resultados da aplicação de um produto educacional, elaborado em um Programa de Pós-Graduação em Ensino de Ciências Humanas, Sociais e da Natureza, no que se refere à produção textual em Inglês, a partir do gênero fotopoema, com o uso da rede social Facebook. A investigação caracteriza-se, basicamente, como pesquisa de campo, descritiva, bibliográfica e analítica. Como resultados, foi possível desenvolver em uma turma de alunos do $1^{\circ}$ ano do Ensino Médio a habilidade de $W$ riting por meio do gênero fotopoema e divulgar os trabalhos em uma página da rede social Facebook e os alunos se sentiram mais motivados a realizar atividades de Writing na aula de Língua Inglesa.

Palavras-chave: Novas tecnologias; Ensino; Língua Inglesa.

\section{Abstract}

Use of new technologies for textual production of the fotopoema genre in english

This study presents and discusses the results of the application of an educational product, elaborated in a Postgraduate Program in Teaching Human, Social and Nature Sciences, regarding the textual production in English, from the genus photopoem, with the use of Facebook social network. The research is characterized as descriptive, bibliographical and analytical research. As a result, it was possible to develop in a group of students of the 1st year of High School the ability of Writing through the genre fotopoema and disseminate the works in a page of the social network Facebook and the students were shown more motivated to carry out activities of Writing in English language class.

Keywords: New technologies; Teaching; English language.

\section{Resumen}

Uso de las nuevas tecnologías para la producción textual del género fotopoema en inglés

Este estudio presenta y discute resultados de la aplicación de un producto educativo, elaborado en un Programa de Postgrado en Enseñanza de Ciencias Humanas, Sociales y de la Naturaleza, en lo que se 
refiere a la producción textual en Inglés, a partir del género fotopoema, el uso de la red social Facebook. La investigación se caracteriza, básicamente, como investigación de campo, descriptiva, bibliográfica y analítica. Como resultados, fue posible desarrollar en una clase de alumnos del $1^{\circ}$ año de Enseñanza Media la habilidad de Writing por medio del género fotopoema y divulgar los trabajos en una página de la red social Facebook y los alumnos se mostraron más motivados a realizar actividades de Writing en la clase de Lengua Inglesa.

Palabras clave: Nuevas Tecnologías; Educación; Idioma en Inglés.

\section{Introdução}

O contexto escolar encontra-se marcado pelo constante avanço tecnológico da sociedade e a Internet constitui importante recurso no processo de ensino e aprendizagem. Esse fato demanda maior atenção tanto na formação inicial quanto continuada dos professores, visto que, atualmente, faz-se indispensável formação tecnológica para a capacitação docente.

Dessa forma, é importante que o professor seja receptivo às mudanças sociais e ao uso das novas tecnologias com fins didático-pedagógicos. Cope e Kalantziz (2000) observam que as relações de trabalho também mudam e passam a exigir profissionais com iniciativa e pensamento crítico. Dessa maneira, o docente precisa estar em constante busca para acompanhar as mudanças tecnológicas presentes na sociedade.

Os recursos digitais como ferramentas, aplicativos, software e outros constituem-se como meios de interação, reflexão e produção no contexto educacional. As redes sociais, por exemplo, podem auxiliar no processo de ensino-aprendizagem e na participação e engajamento dos alunos nas aulas. Mais especificamente no ensino de línguas, a tecnologia oferece um complemento às propostas de ensino, pois além de proporcionar o contato real com falantes nativos ou aprendizes de segunda língua, desperta o interesse dos alunos e os motiva a realizar diferentes propostas de atividade tanto em sala de aula quanto fora dela.

Tendo em vista o cenário atual, em especial a extensão que as redes sociais representam na vida dos estudantes, surgiu o interesse em saber como o Facebook poderia auxiliar na produção textual em Inglês. Assim, esta pesquisa tem por objetivo apresentar e discutir resultados da aplicação do produto educacional Improving Your Writing Skills, elaborado para aperfeiçoar a prática escrita em Inglês de alunos do Ensino Médio de uma escola particular da cidade de Santa Mariana - PR, a partir do gênero fotopoema e com o uso da rede social Facebook. 


\section{Tecnologias digitais no ensino escolar}

As Tecnologias de Informação e Comunicação (TIC) têm trazido inovações no ensino e na aprendizagem e instituído um novo paradigma na educação, uma vez que estão sendo disponibilizados grandes números de recursos, ferramentas, aplicativos que promovem interação, participação e reflexão por parte de alunos e professores, sobretudo no que se refere ao ensino de língua estrangeira.

O alcance das TIC na sociedade assume proporções 'epidêmicas'. Nos mais diversos recantos, os indivíduos procuram ou são impelidos a utilizar recursos tecnológicos para desempenhar práticas sociais variadas, como fazer compras, movimentar contas bancárias, telefonar e 'até' aprender. Esse fato não somente deixou de ser novidade há algum tempo, como também potencializou o caráter comunicativo do ensino de línguas (VENTROMILLE-CASTRO, FERREIRA, 2016, p. 157).

Com a tecnologia dos computadores em rede, a comunicação mediada pelo computador vem se tornando uma possibilidade pedagógica a mais nos contextos de ensino de línguas. Além de propiciar espaços de comunicação mediada pela escrita, a Internet trouxe possibilidades de superação das dificuldades relacionadas a distância entre aprendizes de línguas estrangeiras e comunidades usuárias destas línguas.

Para Lévy (2003), o uso crescente das tecnologias digitais e das redes de comunicação interativa acompanha e amplia as mudanças contemporâneas das relações com o saber, uma vez que prolonga determinadas capacidades cognitivas humanas (memória, imaginação, percepção). Assim, as tecnologias digitais redefinem seu alcance, seu significado e, algumas vezes, até mesmo sua natureza. Elas acentuam as vantagens que a Internet e suas ferramentas podem trazer para o ambiente escolar e compreendem as diversas possibilidades e metodologias disponíveis para serem utilizadas como recursos pedagógicos no ensino de línguas.

Outro fator evidente no trabalho com recursos digitais é a facilidade da troca de conhecimento entre os agentes envolvidos no processo. A cooperação entre os usuários está presente quando não há um único detentor do conhecimento, e sim a troca e a ajuda mútua entre professores, alunos e colegas. O conhecimento é compartilhado, construído e enriquecido com a contribuição de todos (DAL MOLIN, 2003).

Embora as tecnologias digitais inseridas no contexto escolar ofereçam grande diversidade de recursos para os professores e alunos e colaborem com a promoção de 
situações reais de aprendizagem mais próximas da realidade discente, elas exigem preparação por parte do professor para que ele possa atender a essa demanda. Esse profissional precisa estar preparado para selecionar ferramentas, aplicativos, sites e outras opções, as quais se caracterizam como as mais condizentes com os conteúdos que serão trabalhados em sua disciplina.

Nesse sentido, é necessário que seja ofertada a esse profissional, além de aperfeiçoamento de sua prática pedagógica no que se refere às teorias de ensino, também capacitação para o trabalho com as novas tecnologias no ensino de línguas. Por essa razão, as capacitações em exercício são essenciais, pois a formação inicial dos professores, muitas vezes não é suficiente para dar conta do perfil requerido para o profissional que vai lecionar língua estrangeira a estudantes inseridos em mídias sociais, internet, ambientes virtuais de aprendizagem e outros.

\section{O Facebook como ferramenta para o ensino e aprendizagem de língua inglesa}

Estabelecido em 2004 por Mark Zuckerberg, o Facebook tornou-se uma ampla rede mundial de informação e de comunicação, contendo, em 2012, cerca de um bilhão de usuários ativos, que de acordo com os termos de uso, devem ter no mínimo 13 anos de idade. No que diz respeito ao universo educativo, Alves e Araújo (2013) afirmam que o Facebook oferece potencial significativo, o que permite aos alunos a prática de trabalhos em grupo, admite o compartilhar interativo das aulas, favorece o crescimento da curiosidade e da motivação a propósito dos temas abordados, além de disponibilizar links para textos, vídeos e outros sites de interesse grupal. Ou seja, segundo os autores, o Facebook constitui um espaço que favorece a construção colaborativa do conhecimento, o compartilhamento de informações e a cocriação de ideias.

Além disso, o próprio Facebook criou uma página específica para educadores (http://www.facebook.com/education), de maneira que eles possam conhecer mais acerca desta rede social e a utilizar como ferramenta para o ensino e aprendizagem. Segundo Rabello e Haguenauer (2011), dentre as oito experiências relatadas em sua pesquisa, uma delas aborda as potencialidades e limitações do Facebook, demonstrando que tal rede social proporciona possibilidades de aprendizagem e trabalho colaborativo. Estes autores ressaltam que essa ferramenta: 
(a) promove uma cultura comunitária virtual e aprendizado social; (b) oferece suporte para abordagens de aprendizagem inovadoras; (c) motiva os alunos; (d) permite a apresentação de conteúdo significante por meio de materiais autênticos; e (e) oferece comunicação síncrona e assíncrona (RABELLO, HAGUENAUER, 2011, p. 13).

O Facebook pode proporcionar ampla interatividade e potencial pedagógico, facilitando e aperfeiçoando as metodologias de ensino. Para Rabello e Haguenauer (2011), as redes sociais são sites na Internet que permitem a interação e a comunicação entre pessoas de diferentes grupos sociais. Assim, pensando em utilizar a rede social Facebook para promover uma interação no contexto escolar, partiu-se de alguns princípios que norteiam a atividade mediadora do professor para a realização deste trabalho.

Allegrette et al. (2012) aludem que o Facebook apresenta diversas vantagens pedagógicas, tais como a facilidade de conversação, o amparo na diminuição das relações hierárquicas de poder entre professor e alunos, a melhora do grau de relacionamento, o suporte à interação entre estudantes pondo fim ao discurso limitado professor-aluno e a viabilidade de suprir sistemas de gerenciamento de aprendizagem formais como o moodle e Blackboard. Além dessas características comunicacionais e de interatividade, Allegrette et al. (2012) indicam a possibilidade de o Facebook ser utilizado em uma aprendizagem com currículo flexível, além dos muros da escola, ultrapassando o tempo e o espaço formais, proporcionando novas maneiras de tratar o conhecimento no contexto escolar num modelo de escola expandida.

Desse modo, por crescerem no mundo "sempre ligado" da mídia interativa, da Internet e das tecnologias de mídia social, no momento atual, os discentes exibem perspectivas e estilos de aprendizagem diferentes das gerações anteriores. De acordo com Phillips, Baird e Fogg (2012), a ampla utilização de tecnologias sociais e móveis proporciona aos adolescentes uma chance única de fazer uso de ferramentas como o Facebook para estabelecer grupos de aprendizagem auto-organizados ou redes de aprendizagem pessoal (PLN).

\section{O gênero fotopoema}

Antigamente, buscava-se algo que expressasse facilmente a beleza e a simplicidade da vida, das experiências vividas e do que se enxergava. Desse modo, 
compreendeu-se que só era possível elucidar todas estas coisas de maneira única, por meio da poesia, porquanto igualmente falava Cesário $V_{e r d e}{ }^{1}$, um respeitável poeta português que retratava o que via por meio da poesia, e dizia que pintava quadros com palavras. E realmente pintava, suas poesias entor navam coloração, surrealismo, verdade, aflição, agonia, alegria, liberdade e grandiosidade. Assim, a poesia foi criada com o anseio de conseguir "pintar com palavras”.

Já a fotografia é tudo que abrange técnicas de um conceito mínimo de estética. Pode ser o desejo de transmitir uma ideia de maneira rápida e precisa, sem a obrigação de um desenho prévio ou de escrever um texto. Conforme destaca Flusser (1985, p. 13), “imagens são superfícies que pretendem representar algo”, e a fotografia permite que mesmo um indivíduo pouco alfabetizado possa compreender o objeto, a cena, a situação retratada e extrair dali uma interpretação, ou seja, qualquer indivíduo é capaz de "ler" uma imagem, ou seja, de compreender o que a imagem representa.

De acordo com Flusser (1985), a imagem é um código aberto indefinido suscetível às diversas interpretações que dependem do preparo cultural de cada leitor, entretanto, a existência de um discurso fotográfico ou uma linguagem fotográfica delimita, de certo modo, a pretendida abertura ou liberdade desmesurada de leitura da imagem pelos receptores, sobretudo para aqueles principiados na área, que apreciam a linguagem fotográfica, ainda que se saiba que a imagem é sempre conotativa, símbolos "conotativos".

Dessa maneira, o fotopoema constitui-se da junção da poesia em si e da fotografia. Nele encontram-se um poema sob uma imagem, o que muitas vezes já fala por si, causando um maior impacto no leitor. Rodella (2009) observa que:

A fotografia poética por sua vez nasce do interesse do artista em manifestar algo, em representar a natureza ou de intervir nesta natureza com elementos que despertem uma manifestação qualquer. A foto poética é livre enquanto depende da criatividade sem limites do artista. A intencionalidade do autor deste tipo de imagem é produzir sensações, leituras muito mais nos campos estéticos e sensíveis do que do informativo, e muitas vezes estas imagens são produzidas sem intencionalidade, já que o artista tem uma postura menos "racional" frente à sua obra - o que importa na maioria dos casos é a criatividade, a intuição a sensibilidade, menos que o raciocínio articulado do repórter fotográfico (RODELLA, 2009, p. 02).

\footnotetext{
${ }^{1}$ O poeta português José Joaquim Cesário Verde nasceu em Lisboa no dia 25 de fevereiro de 1855. Conhecido por seus dois últimos nomes, ele é visto como um dos predecessores e grande influência do estilo poético realizado no século XX em Portugal.
} 
De acordo com Camargo (1999), as imagens expressivas ou poéticas encontram referência na cultura e no repertório coletivo, “dando a estas imagens uma existência autônoma que não se restringe aos seus usos funcionais ou documentais, mas sim às suas potencialidades expressivas e, portanto, estéticas" (CAMARGO, 1999, p. 27). O artista enquanto enunciador provoca os argumentos e dispositivos que serão contemplados, compreendidos pelos leitores de sua obra, traçando de maneira intencional ou intuitiva as narrativas possíveis, determinando o tema, o assunto, os elementos significantes que podem não ter uma coerência, como no movimento surrealista, mas que podem ser percebidos por quem contempla a obra.

Na proposição de Santos (2013), Koch e Elias (2012), gêneros textuais são formas linguísticas verbais associadas ou não às formas linguísticas não verbais - que as pessoas usam para se relacionar nos diversos ambientes sociais. Cada gênero apresenta aspectos essenciais como: nome específico; contexto de produção e recepção; tema; função; organização e linguagem. São exemplos de gêneros: conversa espontânea, bilhete, poema, notícia, resumo, artigo científico, história em quadrinhos, fotolegenda, fotopoema, infográfico, e-mail, teleconferência, anúncio publicitário, receita culinária, romance e muitos outros.

Com base nos estudos de Santos (2013), expõe-se um quadro-síntese com traços característicos do gênero fotopoema, que precisam ser explorados com alunos, a fim de que possam compreender e produzir este gênero (Quadro).

\section{Procedimentos metodológicos}

Esta seção apresenta a metodologia utilizada para a execução deste estudo. Os tipos de pesquisa utilizados são: descritiva, bibliográfica, de campo, experimental, pesquisa-ação e analítica. Para a efetivação da pesquisa, inicialmente, apresentou-se a proposta à direção da escola na qual seria aplicada a atividade. Posteriormente, selecionou-se o $1^{\circ}$ ano do Ensino Médio. A turma era composta por 19 alunos de aproximadamente 15 anos de idade, distribuídos em meninos e meninas.

A escolha do estabelecimento de ensino e dos participantes deu-se pelo fato de uma das autoras atuar como professora de Língua Inglesa no estabelecimento e verificar que o material didático utilizado com os alunos trazia somente textos para interpretação, com questões objetivas e quase nunca dissertativas. As produções textuais escritas em Língua Inglesa não eram contempladas em nenhum momento no 
Quadro - Traços do gênero textual fotopoema.

\begin{tabular}{|c|c|}
\hline Traços característicos & Gênero textual \\
\hline 1- Nome específico & Fotopoema \\
\hline $\begin{array}{l}\text { 2- Contexto de produção e recepção: } \\
\text { a) autor } \\
\text { b) leitor preferencial } \\
\text { c) suporte } \\
\text { d) tempo de produção } \\
\text { e) local de produção } \\
\text { f) evento deflagrador da produção }\end{array}$ & $\begin{array}{l}\text { a) internautas escolares ou não escolares e poetas } \\
\text { amadores ou profissionais. } \\
\text { b) pessoas que interagem pelas redes sociais digitais e que } \\
\text { gostam de poesia. } \\
\text { c) Internet; computador; smartphones, tablets e livros. } \\
\text { d) momento anterior à publicação. } \\
\text { e) provavelmente a residência do autor ou a escola/academia. } \\
\text { f) existem diversos, por exemplo, uma ação espontânea, } \\
\text { ou um cumprimento de atividade escolar. }\end{array}$ \\
\hline 3- Tema/conteúdo & $\begin{array}{l}\text { Normalmente envolve assuntos relacionados aos } \\
\text { sentimentos, como amor, saudade, entre outros. }\end{array}$ \\
\hline 4- Função/objetivo & $\begin{array}{l}\text { Associar a poesia à fotografia, com a intenção de despertar } \\
\text { emoção, sentimentos. }\end{array}$ \\
\hline 5- Organização básica/estrutura & $\begin{array}{l}\text { Apresenta uma foto colorida ou em preto e branco, como } \\
\text { primeiro plano, e um poema disposto sob ela, referente ou } \\
\text { não à imagem. }\end{array}$ \\
\hline 6- Linguagem/estilo & $\begin{array}{l}\text { Linguagem mista (imagens e palavras) com predomínio } \\
\text { da escrita formal, clara, coerente, coesa, concisa, } \\
\text { normalmente empregada em } 1^{\text {a }} \text { pessoa, com um grau } \\
\text { elevado de autoria. }\end{array}$ \\
\hline
\end{tabular}

Fonte: Elaboração dos autores com base em Santos (2013).

material didático. A falta de tempo em sala de aula para se trabalhar a habilidade de Writing constituiu outro ponto motivador para a elaboração da proposta, que visa à produção dos alunos fora do ambiente escolar, utilizando ferramentas tecnológicas de fácil acesso e presente na vida desses discentes.

O fato de poder praticar a escrita em Inglês como atividade complementar ao material também se instituiu um desafio, pois o material era extenso e sempre cobrado que o professor o cumprisse até o final do bimestre. Entretanto, outro fator motivador para a elaboração da proposta de pesquisa foi a possibilidade de criação 
de um ambiente em que os alunos pudessem realizar produções textuais em Língua Inglesa, reconhecer sua capacidade e serem reconhecidos. Uma vez que, além de produzirem textos utilizando ferramentas digitais, os trabalhos ficariam acessíveis a um público amplo e diversificado, o que poderia motivar os alunos a realizar boas práticas de escrita.

No primeiro encontro de aplicação da proposta entregou-se um termo de autorização aos alunos para que fosse assinado pelos pais ou responsáveis, em razão de que os nomes seriam expostos na página do Facebook. Os alunos não apresentaram resistência para aceitar a proposta, nem para realizarem as produções que lhes foram solicitadas. A princípio, existiu receio por parte de alguns, que diziam que não conseguiriam escrever em inglês. No entanto, ao realizar uma dinâmica com a turma para avaliar a quantidade de palavras que conheciam em Língua Inglesa, o resultado os deixou mais confiantes.

Na sequência, apresentou-se aos alunos o Improving Your Writing Skills, espaço criado no Facebook para postar as atividades que seriam desenvolvidas com os discentes. Também se divulgou o site Teacher's Guide ${ }^{2}$, no qual estavam contidos os procedimentos para aplicação da proposta. Foi necessária a criação deste site, haja vista que a rede social Facebook não pode ser considerada um produto educacional por ser uma plataforma já existente, desse modo, foi considerado suporte para o trabalho com a produção textual em Língua Inglesa e de divulgação dos gêneros produzidos pelos alunos.

A seguir, foram mostradas as etapas para a realização das produções textuais. Para facilitar a comunicação fora do contex to escolar, tanto para tirar dúvidas, quanto para a correção das produções antes de postá-las na página, criou-se um grupo no WhatsApp. Ressalta-se que, para que realmente houvesse participação dos alunos nas atividades propostas, houve atribuição de nota para cada produção. Até mesmo porque tal proposta constituía parte do planejamento escolar, no qual os conteúdos abordados revisavam assuntos como verbo To Be, Wh-Questions, Personal Pronous, entre outros.

Explicou-se a eles qual era o objetivo das atividades e como surgira a ideia de desenvolver a proposta, explanou-se também como ela seria desenvolvida e analisada. Os alunos participantes receberam bem a proposta e concordaram em

${ }^{2}$ Disponível em: http://luhidalgo.wixsite.com/iyws. 
participar da atividade, ressaltando que seria interessante estudar Língua Inglesa utilizando um material diferente da apostila, principalmente por se tratar de uma ferramenta digital.

Após a explicação da atividade, expôs-se à turma qual seria o tema de estudo, o gênero fotopoema, elucidando-se as características do gênero e o que era esperado que fizessem: definir a imagem que seria usada como inspiração para o poema; delimitar o tema do poema; escrever o poema propriamente dito, pensando no que gostariam de dizer ao leitor do fotopoema, para em seguida escrevê-lo em inglês; inserir o texto na imagem, finalizando o fotopoema.

Além da explicação em sala, disponibilizou-se a eles no grupo privado da turma no Facebook uma apresentação de slides sobre o gênero, que havia sido preparada para ser passada na sala de vídeo, que no dia estava sendo utilizada pelo professor de música. Phillips, Baird e Fogg (2011, p. 11) observam que "ao usar um grupo do Facebook para complementar o que você ensina na sala de aula, você fornece aos alunos oportunidades de aprendizagem sob demanda”.

Para auxiliar os estudantes na escrita das produções, utilizou-se como referência o capítulo 5 - Decisões preliminares sobre o texto a produzir - da obra Técnicas de Redação - O que é preciso saber para bem escrever, de Garcez (2004). Antes de realizarem as produções, foram questionados com algumas perguntas, tais como:

- Quais os objetivos do texto que vou produzir?

- Que informações quero transmitir?

- Qual o gênero de texto mais adequado aos meus objetivos?

- Que estruturas de linguagem devo usar? (GARCEZ, 2004, p. 61).

Essas questões foram traduzidas para a Língua Inglesa e postadas também na página do Facebook para serem lembrete constante aos alunos, não apenas para as produções que deveriam realizar no momento da aplicação do produto, como também para todas as outras que tiverem de realizar durante o percurso escolar e para servir de auxílio para o público que acessasse a página.

Como um dos encontros destinou-se apenas para sanar as dúvidas a respeito da produção e do vocabulário que deveria ser utilizado, a professora-pesquisadora 
criou um vídeo tutorial ${ }^{3}$ fazendo seu próprio fotopoema, com utilização do aplicativo Paint para editar a foto selecionada e o Microsoft Office Word para editar o texto que seria inserido na foto.

O link do vídeo tutorial foi enviado no grupo do WhatsApp, que também estava sendo utilizado para mediar a realização do fotopoema e auxiliar na realização das produções, no qual poucos alunos se manifestaram para tirar dúvidas ou buscar esclarecimentos. O link do vídeo tutorial também foi disponibilizado no grupo fechado da turma no Facebook, para que todos tivessem acesso.

Foram utilizados alguns minutos da aula para comentar sobre o gênero e explicar como fariam o seu fotopoema, bem como para ressaltar que teriam de gravar a produção, em razão de que a escola em questão não possuía sala de informática para que produzissem no ambiente escolar permitindo que a professora pudesse filmar e comprovar a aplicação de seu produto. O prazo para essa produção foi de duas semanas.

No encontro seguinte, discutiu-se a respeito da produção e solicitou-se que os alunos comentassem sobre a experiência. A produção foi entregue apenas por sete alunos. Mesmo atribuindo nota, os demais justificaram dizendo que, como estavam em semana de provas, o prazo para a entrega da produção foi pequeno demais, ainda mais por terem que filmar: muitos alegaram não terem alguém para os ajudarem com a filmagem. As produções foram postadas na página do Facebook e infelizmente o prazo para os demais não pôde ser estendido, uma vez que o bimestre estava acabando e era necessário ainda aplicar as provas e recuperações finais.

Nesse último encontro, recebeu-se o feedback dos alunos por meio de diálogo em sala de aula em que toda a turma estava presente, o que foi de extrema importância para a pesquisa. Por meio desta conversa, os alunos puderam compartilhar suas impressões a respeito da realização das produções, das dificuldades e das facilidades encontradas durante este percurso e sua experiência em realizar atividades que fugissem um pouco da utilização apenas do material didático. Infelizmente, não foi possível realizar a refacção do gênero devido à falta de tempo, no entanto, houve conexão gramatical com os assuntos que deveriam ser trabalhados no bimestre, ou seja, as produções cumpriram com os conteúdos da ementa.

\footnotetext{
${ }^{3}$ Disponível em: <http://www.screencast.com/users/LuIdalgo/folders/Default/media/437e530a-30bb-4c33-9b51-b67c6785d3c5>.
} 


\section{Apresentação e análise dos resultados}

Nesta seção apresentam-se os resultados da aplicação do produto educacional Improving Your Writing Skills ao primeiro ano do Ensino Médio de uma escola particular da cidade de Santa Mariana - PR, no que se refere à produção de fotopoemas. A análise considerou os critérios de engajamento, de uso da língua, de pontos positivos levantados pelos alunos e da apropriação das características dos gêneros. No decorrer de toda aplicação, a pesquisadora realizou anotações com o propósito de utilizá-las para a análise dos dados.

\section{Produção dos fotopoemas}

Os resultados obtidos com a elaboração dos fotopoemas não foram tão satisfatórios e dentre os fatores que, segundo os alunos, contribuíram para isto estão o fim do bimestre, as provas mensais e bimestrais, os trabalhos avaliativos (não só da disciplina de Língua Inglesa, como também das demais), e o curto prazo para a entrega, que foi de duas semanas. Assim, em termos de engajamento, apenas sete dos 19 alunos entregaram a produção do gênero fotopoema, constituindo 37\% da turma. O Gráfico exibe a porcentagem de alunos que realizaram a produção.

\section{Gráfico - Alunos que realizaram a produção dos fotopoemas.}

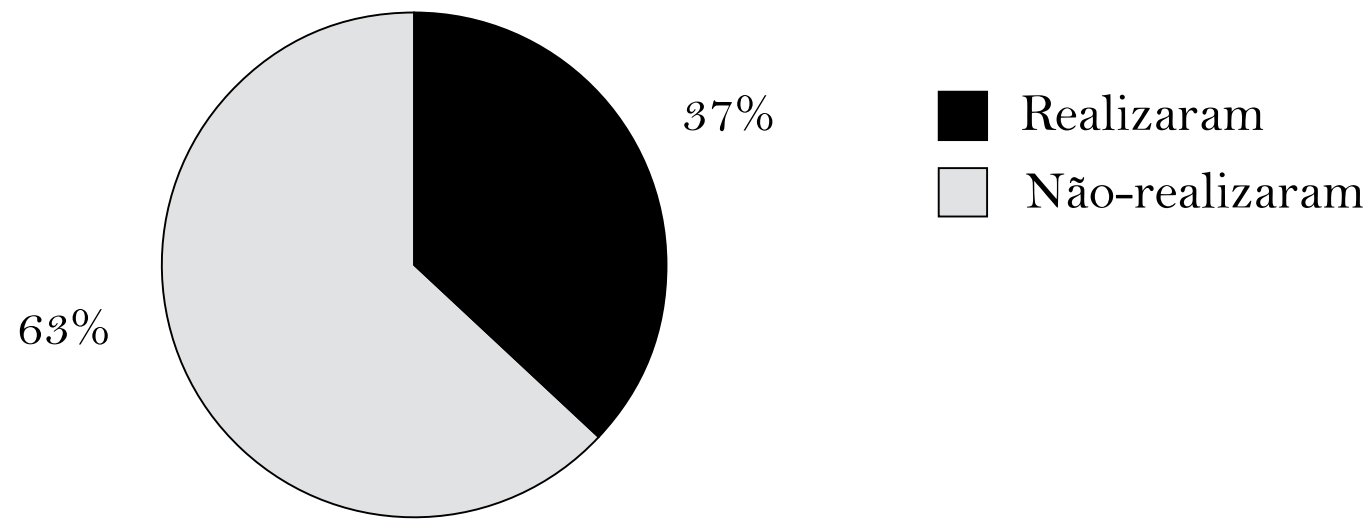

Fonte: Elaboração dos autores.

Em termos de uso da língua, houve certa dificuldade em se produzir o fotopoema, pois os alunos não conheciam bem o gênero, mesmo quando associado à junção do gênero poesia com a fotografia. Também o fato de terem de escrever um poema constituía um desafio aos adolescentes participantes da pesquisa, que apresentaram certa resistência em expressar sentimentos por meio de palavras. Sendo 
assim, percebe-se que a dificuldade na realização da produção do fotopoema foi com o conteúdo e não com o uso da tecnologia em si.

Após a realização da atividade, foi proposto um momento na aula seguinte para que os alunos comentassem sobre a experiência. No que diz respeito aos pontos positivos levantados pelos alunos, todos alegaram que escrever algo com o objetivo de provocar diferentes emoções nos leitores era demasiadamente complicado.

Sobre os traços característicos do gênero fotopoema, constatou-se ao analisar as produções que, mesmo tendo certa dificuldade na produção deste gênero, os alunos conseguiram atingir o objetivo comunicativo, cumprindo com as características ligadas à linguagem, à estrutura e à função do gênero em questão. Devido ao fotopoema não ser um gênero com o qual os alunos têm contato constantemente, acredita-se que esse fato justifica a baixa adesão do gênero pelos discentes.

Os fotopoemas foram postados na página da rede social Facebook. O prazo não pôde ser estendido, pois o bimestre estava acabando e a professora-pesquisadora precisava aplicar suas provas e recuperações finais.

Acerca de se utilizar essa rede social no contexto escolar, Phillips, Baird e Fogg (2012) analisam que:

Ao considerar o uso do Facebook para criar oportunidades de aprendizagem móvel (mLearning), também é essencial que os educadores tenham um entendimento melhor de como a juventude menor de idade urbana se conecta e interage na $W e b$ para que possam criar experiências digitais mais inclusivas (PHILLIPS, BAIRD, FOGG, 2012, p. 14).

A respeito disso, Rabello e Haguenauer (2011) destacam que o aprendizado eletrônico (e-Learning), assim como a aprendizagem móvel (mLearning), estão transformando de forma significativa os ambientes e contextos de aprendizagem. Ou seja, é preciso que os professores se atentem a essas novas tecnologias que vêm crescendo cada vez mais dentro do próprio ambiente escolar, para empregá-las corretamente em seu benefício. No entanto, mesmo utilizando a tecnologia para a realização desta atividade, a maioria dos alunos não realizou a produção do fotopoema.

No último encontro presencial, pôde-se discutir a respeito da aplicação do produto educacional, sendo que $85 \%$ da turma observaram que a iniciativa de propor novos métodos para se ensinar Língua Inglesa, que vão além da apostila, assim como a utilização de ferramentas tecnológicas e de redes sociais, foi moti- 
vadora: os outros $15 \%$ consideraram a proposta inovadora, no entanto alegaram que encontraram algumas dificuldades por se tratar de algo novo e por terem que produzir os gêneros fora do ambiente escolar sem o auxílio da professora.

A seguir, são registradas algumas das produções textuais do gênero fotopoema realizadas pelos alunos participantes desta pesquisa (Figuras 1, 2, 3 e 4).

Figura 1 - Fotopoema produzido pela aluna JM.

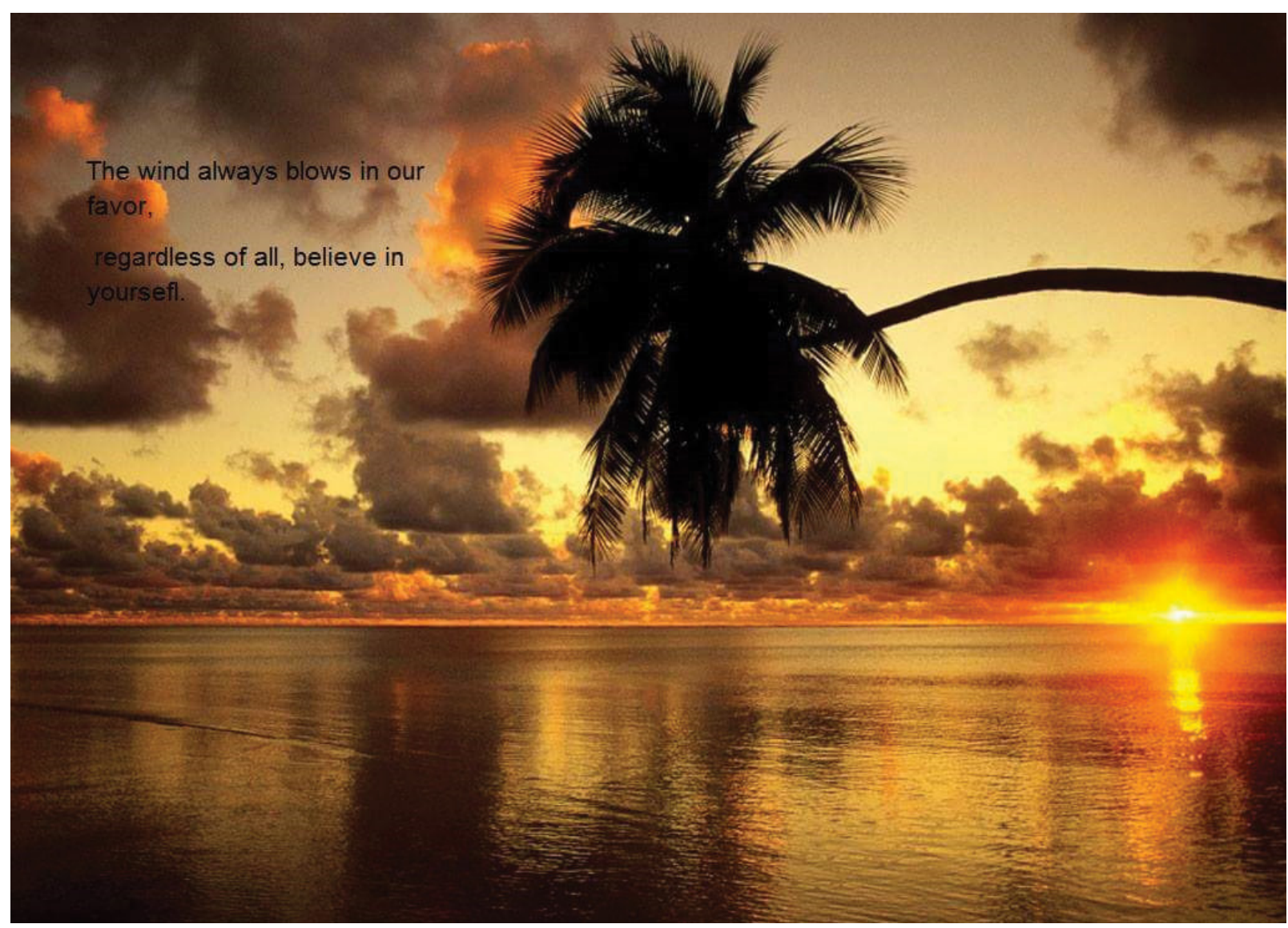

Fonte: Arquivo pessoal dos autores. 
Figura 2 - Fotopoema produzido pela aluna BD.

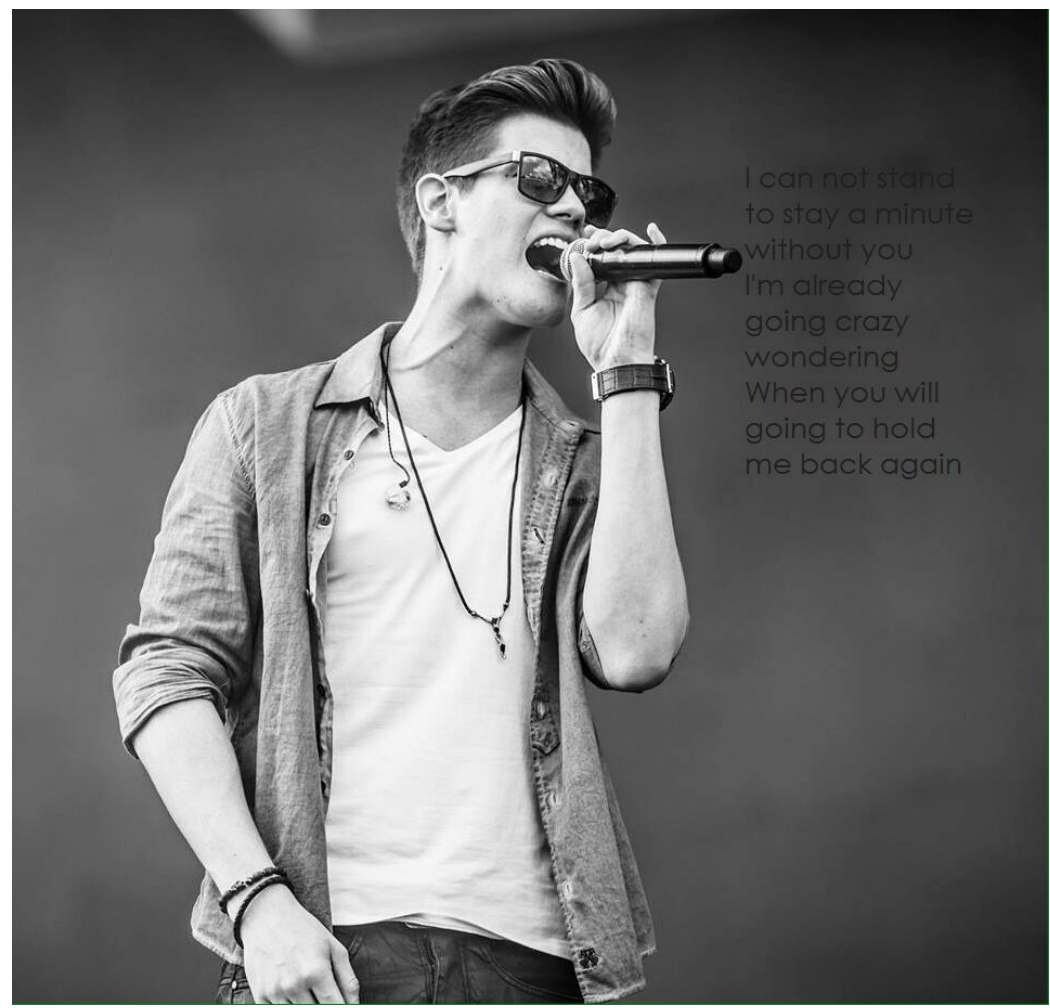

Fonte: Arquivo pessoal dos autores.

Figura 3 - Fotopoema produzido pela aluna JF.

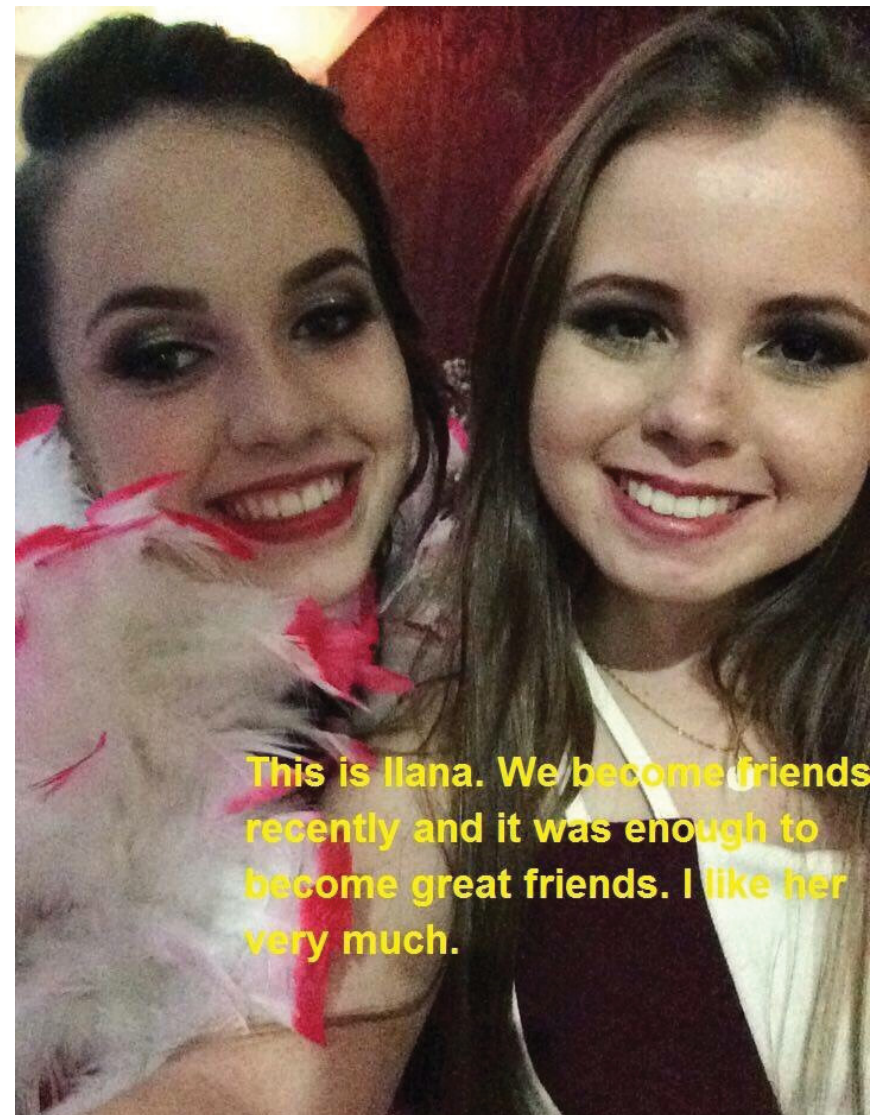

Fonte: Arquivo pessoal dos autores. 
Figura 4 - Fotopoema produzido pelo aluno GB.

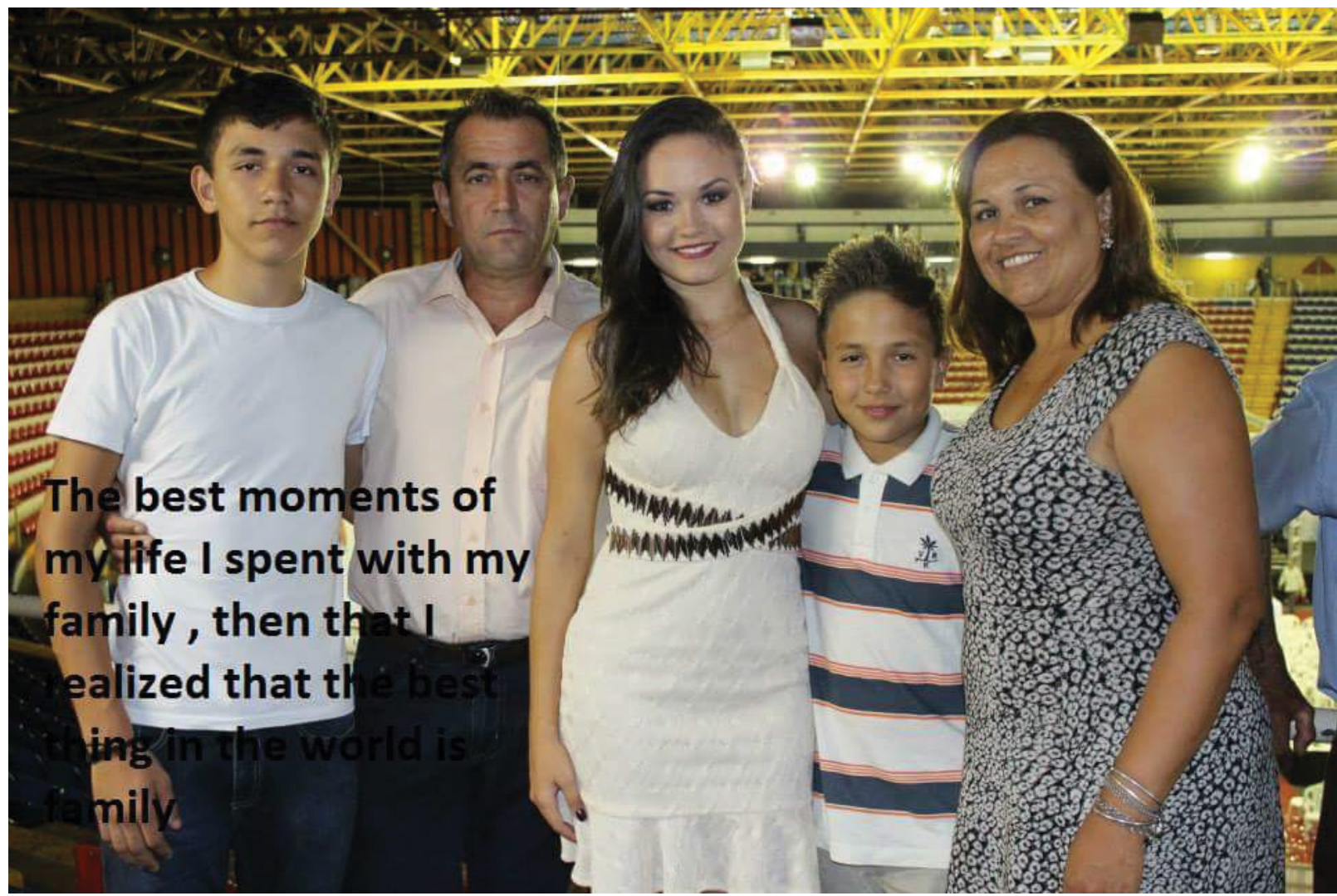

Fonte: Arquivo pessoal dos autores.

Embora apenas $37 \%$ da turma tenham realizado a produção, os pontos positivos obtidos com esse trabalho foram significativos, em razão de que os alunos puderam utilizar dispositivos móveis para aprimorar a habilidade de Writing, como uma nova proposta metodológica. Eles dedicaram também tempo extraclasse para a realização dessas atividades; foram pesquisadores e protagonistas de sua própria aprendizagem; e puderam tornar públicas suas produções, contando com o reconhecimento da direção e coordenação da escola e demais colegas.

Buscar a autonomia do aluno é muito importante para a construção de um conhecimento significativo, e sabe-se que a autonomia no aprendizado é considerada uma característica da educação pós-moderna (GRADDOL, 2006). Tendo em vista que o foco da pesquisa consistia em aprimorar a Língua Inglesa dos alunos utilizando recursos digitais, reconhece-se que grande parte da informação mundial circula em inglês (GRADDOL, 2006) e na Internet (FINARDI, PREBIANCA, MOMM, 2013), podendo-se considerar assim o Facebook como "um importante espaço de acesso, prática e produção de informação nessa língua” (ARAÚJO, LEFFA, 2016, p. 101). 
Pôde-se notar que, dentre as dificuldades com que os alunos se depararam no decorrer das produções, encontra-se a insegurança, por ser a primeira vez que tiveram a tarefa de escrever em Língua Inglesa sem ter o auxílio da professora o tempo todo, estando fora do ambiente escolar, embora o uso de ferramentas digitais e redes sociais para a prática da Língua Inglesa contribuísse para este exercício.

Phillips, Baird e Fogg (2012) observam que trazer o Facebook para a sala de aula:

[...] pode fornecer aos alunos a oportunidade de apresentar suas ideias, conduzir discussões on-line e colaborar de forma efetiva. Além disso, o Facebook pode ajudar você, como educador, a se familiarizar com os estilos de aprendizagem digital dos seus alunos. Por exemplo, isso pode facilitar a colaboração entre os alunos e fornecer maneiras inovadoras para você envolver os alunos em sua matéria (PHILLIPS, BAIRD, FOGG, 2012, p. 3).

Os resultados mostram que se o professor planejar sistematicamente suas aulas, incluir tecnologia, utilizar dispositivos móveis em suas atividades, os alunos se sentirão mais motivados e empenhados em participar das aulas. Além do mais, eles precisam estar preparados para trabalhar com as redes sociais e com os dispositivos móveis, os quais vêm crescendo cada dia mais e tomando conta da vida dos alunos, porquanto "ensinar e aprender exigem hoje muito mais flexibilidade espaço-temporal, pessoal e de grupo, menos conteúdos fixos e processo mais abertos de pesquisa e de comunicação" (MORAN, 2000, p. 29).

\section{Considerações finais}

Os resultados mostram que, apesar da pouca adesão ao gênero fotopoema pelos alunos, o uso da rede social Facebook nas aulas de Língua Inglesa estimulou os alunos, e salientam também que a formação adequada por parte do docente auxilia para a eficácia de atividades como essas. Ademais, os discentes tiveram contato não só com o Facebook, mas também com outros recursos, como o WhatsApp, por exemplo, que foi utilizado para tirar dúvidas acerca da produção textual, além dos diferentes gêneros textuais abrangidos por essas ferramentas, as quais contribuem ainda mais para a prática escrita em inglês.

O uso das novas tecnologias, com orientação e direcionamento colaborou para o ensino de Língua Inglesa no Ensino Médio, o trabalho realizado incluindo a rede social Facebook proporcionou aos estudantes o contato direto com os recursos digitais e com a Língua Inglesa por meio das produções textuais realizadas e divulgadas com o auxílio de ferramentas tecnológicas. 
A Internet pode auxiliar o professor a aprimorar métodos e técnicas de ensino, e para tal, além de preparação, ele deve contar com a disponibilidade de recursos tecnológicos tanto na escola, quanto fora dela, para que o acesso possa ser proporcionado a todos de maneira igualitária. No entanto, ainda existem fatores de sala de aula (presencial) que impedem que eles aproveitem esses recursos para aprender, como a falta dessas ferramentas tecnológicas, por exemplo. Por fim, o professor pode fazer uso da tecnologia de maneira que ela contribui para ampliar conteúdos, a fim de problematizar e criar condições para que os alunos se vejam no foco do processo de ensino e aprendizagem.

\section{Referências}

ALLEGRETTE, S. M. M. et al. Aprendizagem nas redes sociais virtuais: o potencial da conectividade em dois cenários. Cet: Revista Contemporaneidade Educação e Tecnologia, São Paulo, v. 1, n. 2, p. 53-60, abr. 2012.

ALVES, T. P.; ARAÚJO, R. O moodle e o facebook como espaços pedagógicos: percepções discentes acerca da utilização destes ambientes. Em Teia: Revista de Educação Matemática e Tecnológica Iberoamericana, v. 4, n. 2, p. 1-16, 2013.

ARAÚJO, J.; LEFFA, V. Redes sociais e ensino de línguas: o que temos de aprender? São Paulo, SP: Parábola, 2016.

CAMARGO, I. A. Reflexões sobre o pensamento fotográfico. Londrina, PR: Universidade Estadual de Londrina, 1999.

COPE, B.; KALANTZIS, M. Multiliteracies: literacy learning and the design of social futures. London: Routledge, 2000.

DAL MOLIN, B. H. Do tear à tela: uma tessitura de linguagens e sentidos para o processo de aprendência. 2003. Tese (Doutorado em Engenharia da Produção, Área de Concentração em Mídia e Conhecimento) - Universidade Federal de Santa Catarina, Florianópolis, SC, 2003.

FINARDI, K. R.; PREBIANCA, G. V.; MOMM, C. F. Tecnologia na educação: o caso da internet e do inglês como linguagens de inclusão. Cadernos do IL, Porto Alegre, n. 46, p. 193-208, jun. 2013. https://doi.org/10.22456/2236-6385.35931

FLUSSER, V. Filosofia da caixa preta. São Paulo, SP: Hicitec, 1985. 
GARCEZ, L. H. C. Técnica de redação: o que é preciso saber para bem escrever. 2. ed. São Paulo, SP: Martins Fontes, 2004.

GRADDOL, D. English next: why global english may mean the end of "english as a foreign language”. London: British Council, 2006. Disponível em: <http://www.britishcouncil.org/learning-research-english-next.pdf>. Acesso em: 18 maio 2016.

KOCH, I. G. V.; ELIAS, V. M. Ler e escrever: estratégias de produção textual. 2. ed. São Paulo, SP: Contexto, 2012.

MORAN, J. M. Ensino e aprendizagem inovadores com tecnologias audiovisuais e telemáticas. In: MORAN, J. M.; BEHRENS, M. A. Novas tecnologias e mediação pedagógica. 19. ed. Campinas, SP: Papirus, 2000. p. 11-6.PHILLIPS, L. F.; BAIRD, D.; FOGG, B. J. Facebook para educadores. Facebook in Education, 2012. Disponível em: <http://lantec.fae.unicamp.br/ed88/Xconteudos-digitais/arquivos/facebook-para-educadores-guia-PT.pdf>. Acesso em: 2 jun. 2016.

RABELLO, C. R. L.; HAGUENAUER, C. Sites de redes sociais e aprendizagem: potencialidades e limitações. Portal EducaOnline, Rio de Janeiro, v. 5, n. 3, p. 19-43, set./dez. 2011.

RODELLA, C. A. A intencionalidade da Imagem fotográfica poética e da imagem fotográfica no Jornalismo. In: ENCONTRO NACIONAL DE ESTUDOS DA IMAGEM, 2, 2009, Londrina. Anais... Londrina: Universidade Estadual de Londrina, 2009.

SANTOS, G. J. F. Elementos de argumentação na produção de gêneros textuais no ensino médio. 2013. Tese (Doutorado em Estudos da Linguagem) — Universidade Estadual de Londrina, Londrina, PR, 2013.

VENTROMILLE-CASTRO, R.; FERREIRA, K. S. Redes sociais na formação de professores de línguas. In: ARAÚJO, J.; LEFFA, V. (Orgs.). Redes sociais e ensino de línguas: o que temos de aprender? São Paulo, SP: Parábola, 2016.

Submetido Submissão em: 29-03-2019

Aceito em: 29-05-2019 